Article

\title{
Low-Temperature Rheological Properties and Microscopic Characterization of Asphalt Rubbers Containing Heterogeneous Crumb Rubbers
}

\author{
Mingfeng Chang ${ }^{1, *} \mathbb{C}$, Yixing Zhang ${ }^{1}$, Jianzhong Pei ${ }^{2}$, Jiupeng Zhang ${ }^{2} \oplus$, Min Wang ${ }^{1}$ and \\ Fugui $\mathrm{Ha}^{1}$ \\ 1 Department of Materials Science and Engineering, School of Materials Science and Engineering, \\ Chang'an University, 2nd Ring Rd South East Section, Xi'an 710064, China; 2020131065@chd.edu.cn (Y.Z.); \\ 2017902514@chd.edu.cn (M.W.); 2018901708@chd.edu.cn (F.H.) \\ 2 Key Laboratory for Special Area Highway Engineering of Ministry of Education, Chang'an University, \\ 2nd Ring Rd South East Section, Xi'an 710064, China; pei@chd.edu.cn (J.P.); zhjiupeng@chd.edu.cn (J.Z.) \\ * Correspondence: mfchang@chd.edu.cn; Tel.: +86-029-8233-7342; Fax: +86-029-8233-7340
}

Received: 10 August 2020; Accepted: 14 September 2020; Published: 16 September 2020

check for updates

\begin{abstract}
Asphalt rubbers mixed with untreated and plasticized crumb rubbers and a compounding coupling agent were investigated in this study. The low-temperature rheological properties of asphalt rubbers at different aging levels were tested using a dynamic shear rheometer (DSR). An interconversion between linear viscoelastic material functions was used to obtain converted evaluation indexes for the asphalt rubbers at low temperatures. Lastly, the physicochemical characteristics and the microscopic morphology of the asphalt rubbers were evaluated using Fourier transform infrared spectroscopy (FTIR) and scanning electron microscopy (SEM), respectively. In conclusion, the storage moduli of the asphalt rubbers containing heterogeneous crumb rubbers increased with the plasticized crumb rubber content and the aging level. The converted relaxation moduli were consistent with the change trend of the storage moduli, and the relaxation rate decreased as the plasticized crumb rubber content and the aging level increased. The process of mixing the base asphalt with crumb and plasticized crumb rubbers was physical blending, and the effect of aging on the absorption peak change of asphalt rubber with plasticized crumb rubbers was less than that of asphalt rubber with ordinary crumb rubbers. Aging deteriorated the blending between the crumb rubber and the base asphalt, and a distinct interface appeared between the crumb rubber and the base asphalt. The particle cores of the plasticized crumb rubber in the asphalt rubber were difficult to maintain. Furthermore, as the plasticized crumb rubber content increased, more fine particles stripped off the plasticized crumb rubber after aging.
\end{abstract}

Keywords: asphalt rubber; heterogeneous crumb rubbers; rheological property; microscopic characterization; linear viscoelastic material functions

\section{Introduction}

Crumb rubber prepared by waste rubber tires can be effectively combined with a base asphalt in asphalt rubber pavement, which saves resources and presents an environmentally sustainable treatment for hundreds of millions of waste tires produced each year. There are great differences in the compositions of crumb rubber due to the different composition of waste tires, which affects the performance of asphalt rubber [1,2]. Moreover, the poor compatibility between crumb rubber and asphalt in a traditional asphalt rubber results in low performance. However, plasticization of untreated crumb rubbers cleaves existing cross-links. The resulting short molecular chains can move and unfold easily in the base asphalt, which improves blending with the base asphalt. 
An increasing number of studies have been carried out on asphalt rubber for use as a road material [3-5]. Multistress creep recovery and frequency sweep tests were used to determine the rheological properties, i.e., the high-temperature and fatigue properties, of asphalt rubber mixed with a warm agent and a liquid antistripping agent, as well as of SBS (styrene-butadiene-styrene) biorubber asphalt [6-8]. Zhang et al. evaluated the high-temperature performance of asphalt rubber using dynamic shear rheometry and a multistress creep recovery test [9]. Wang et al. used temperature sweep and multistress creep recovery tests to evaluate the high-temperature performance of asphalt rubber treated with bio-oil [10]. Pei et al. investigated the high-temperature rheological properties of asphalt rubber containing crumb rubber that had been treated with bio-oil and zinc stearate [11,12]. Singh et al. added different crumb rubber contents to a recycled asphalt binder and used multistress creep recovery and linear amplitude sweep tests to evaluate the high-temperature rut-resistance of the asphalt rubber $[13,14]$. Xiao et al. found that the high-temperature rheological properties of asphalt rubber were significantly improved by the addition of plasma-treated crumb rubber [15]. Ameri et al. used a linear amplitude sweep test to determine the viscoelastic fatigue characteristics of asphalts modified by crumb rubber and SBS [16]. Yu et al. comprehensively investigated the fatigue performance of asphalt rubber using the fatigue factor index, a linear amplitude sweep test, an indirect tensile fatigue test and a four-point bending beam test [17].

The sensitivity of asphalt rubber to temperature was evaluated using a bending beam rheometer (BBR) and a dynamic shear rheometer (DSR) to determine the low-temperature evaluation index and the mechanism by which particles affect the high-temperature rheological properties of asphalt rubber $[18,19]$. He et al. evaluated the rheological properties of a warm mix Sasobit asphalt rubber at high, medium and low temperatures [20,21]. Puga et al. investigated the low-temperature performance of asphalt rubbers prepared with different asphalt binders, crumb rubber contents and coupling agents and determined the impact of the terminal blend (TB) molecular components on the low-temperature performance of asphalt rubber [22-24]. Furthermore, as an additive used for many years, Vestanamer was a thermoplastic polymer with a unique molecular structure, which achieved the cross-linking of crumb rubber and asphalt, and improved the road performance of asphalt rubber and asphalt rubber pavement [25-28].

Summarizing and analyzing the existing research on asphalt rubber, it can be concluded that the current research trends mainly focus on testing the high-temperature rheological properties of asphalt rubber, and the high-temperature performance is improved after adding crumb rubber. But there are few studies on low-temperature performance. In view of the plasticized crumb rubber containing more small molecular composition and the cross-linking effect of Vestanamer, studies on the low-temperature performance of asphalt rubber prepared by mixing untreated and plasticized crumb rubber with Vestanamer have not yet been reported. However, low-temperature cracking is a well-known defect in asphalt pavement. The same problem is encountered with asphalt rubber prepared using untreated and plasticized crumb rubbers. Thus, the low-temperature rheological properties of asphalt rubber prepared using heterogeneous crumb rubbers needs to be investigated together with the microscopic characteristics of the asphalt rubber for different aging levels to elucidate the mechanisms involved in modification and aging. The objective of this study was to investigate the impact of heterogeneous crumb rubbers on the low-temperature rheological properties and physiochemical characteristics of aged asphalt rubbers. The aging mechanism was elucidated by determining the microstructure of asphalt rubber prepared with heterogeneous crumb rubbers.

\section{Materials and Methods}

\subsection{Materials}

\subsubsection{Base Asphalt}

The base asphalt used in this study was SK 90\# with PG $58-22{ }^{\circ} \mathrm{C}$ produced in Korea (South Korea SK Group, Seoul, Korea). The measured basic property indexes and compositions of SK 90\# are 
listed in Tables 1 and 2. The Fourier transform infrared spectrum (Nicolet iS5, Thermo Fisher Scientific, Waltham, MA, USA) of the base asphalt and SEM ((JSM-6010LA, JEOL Ltd., Tokyo, Japan) images of the corresponding microstructure are shown in Figures 1 and 2.

Table 1. Basic property indexes of base asphalt.

\begin{tabular}{|c|c|}
\hline Property Indexes & Tested Results \\
\hline Penetration $\left(25^{\circ} \mathrm{C}, 5 \mathrm{~s}, 100 \mathrm{~g}, 0.1 \mathrm{~mm}\right)$ & 89.8 \\
\hline Softening point $\left({ }^{\circ} \mathrm{C}\right)$ & 44.5 \\
\hline Ductility $\left(15^{\circ} \mathrm{C}, 5 \mathrm{~cm} / \mathrm{min}, \mathrm{cm}\right)$ & $>100$ \\
\hline Residual penetration ratio ( $\%$ ) & 54.01 \\
\hline Quality change $(\%)$ & 0.4 \\
\hline Apparent viscosity $\left(135^{\circ} \mathrm{C}, \mathrm{Pa} \cdot \mathrm{s}\right)$ & 0.594 \\
\hline
\end{tabular}

Notes: RTFOT represents rolling thin film oven test.

Table 2. Compositions of base asphalt.

\begin{tabular}{cc}
\hline Compositions & Tested Results \\
\hline Saturates (\%) & 16.67 \\
Aromatics (\%) & 43.44 \\
Resins (\%) & 26.01 \\
Asphaltenes (\%) & 13.88 \\
\hline
\end{tabular}

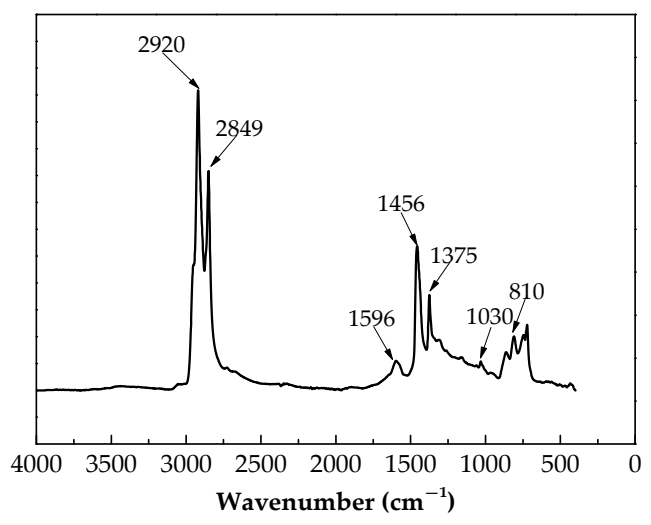

Figure 1. FTIR spectrum of the base asphalt.

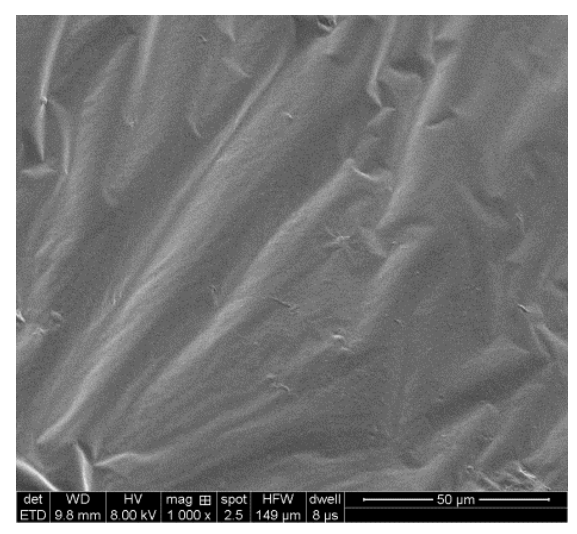

Figure 2. SEM image of the base asphalt.

As shown in Figure 1, the peaks at $2920 \mathrm{~cm}^{-1}, 2849 \mathrm{~cm}^{-1}, 1596 \mathrm{~cm}^{-1}, 1456 \mathrm{~cm}^{-1}, 1375 \mathrm{~cm}^{-1}$, $1030 \mathrm{~cm}^{-1}$ and $810 \mathrm{~cm}^{-1}$ represent asymmetric stretching vibrations of $-\mathrm{CH}_{2}^{-}$, symmetric stretching vibrations of $-\mathrm{CH}_{2}-$, stretching of $\mathrm{C}=\mathrm{C}$, scissor vibration of $-\mathrm{CH}_{2}-$, deformation vibration of $-\mathrm{CH}_{3}$, 
stretching vibration of $\mathrm{S}=\mathrm{O}$ and $=\mathrm{C}-\mathrm{H}$ out-plane deformation vibration of the vinyl group, respectively. Figure 2 shows that the surface of the base asphalt is smooth, and the base asphalt is, in general, a homogeneous structure.

\subsubsection{Crumb Rubber}

In this study, crumb rubbers were produced from waste radial car tires. The mean diameters of untreated and plasticized crumb rubber particles were determined to be $0.25 \mathrm{~mm}$ (60 mesh) by screening, and the plasticized crumb rubber was produced by a constant pressure plasticizing method. The Fourier transform infrared spectra of the untreated and plasticized crumb rubbers are shown in Figure 3, and SEM images of the corresponding microstructures are shown in Figure 4.

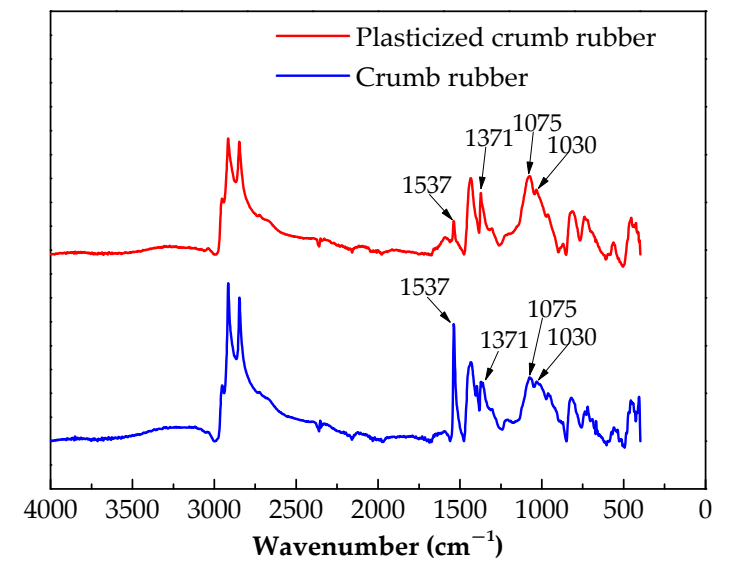

Figure 3. FTIR spectra of the untreated and plasticized crumb rubbers.

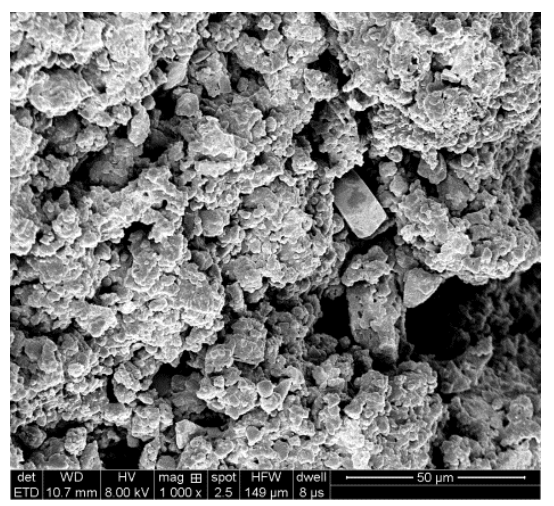

(a)

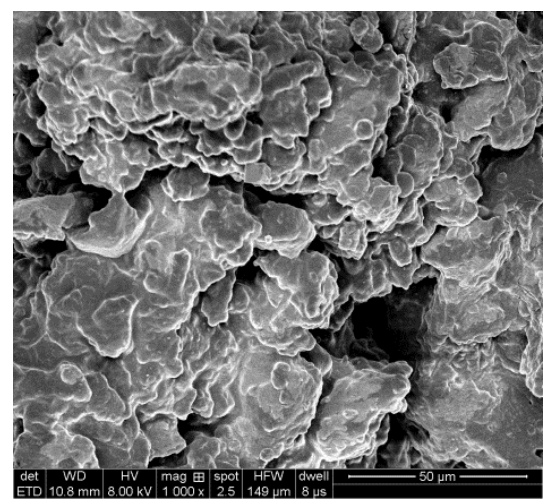

(b)

Figure 4. SEM images of crumb rubbers and plasticized crumb rubbers. (a) Crumb rubbers; (b) plasticized crumb rubbers.

The peaks in the untreated and plasticized crumb rubber spectra in Figure 3 only differ in intensity and not position. The intensity of the $C=C$ stretching vibration at $1537 \mathrm{~cm}^{-1}$ of the plasticized crumb rubber is lower than that of the untreated crumb rubber, showing the partial cleavage of the $C=C$ bond by plasticization [13]. However, the deformation vibration of the methyl group $-\mathrm{CH}_{3}$ at $1371 \mathrm{~cm}^{-1}$ is stronger for the plasticized crumb rubber than for the untreated crumb rubber, which indicates a reduction in the internal cross-linking of plasticized crumb rubber molecules. The increase in the intensity of the $\mathrm{C}-\mathrm{O}$ stretching vibration at $1075 \mathrm{~cm}^{-1}$ and the $\mathrm{S}=\mathrm{O}$ stretching vibration at $1030 \mathrm{~cm}^{-1}$ for the plasticized crumb rubber compared to the untreated crumb rubber reflects the oxidative fracture of C-S and S-S bonds during plasticization. 
Figure 4 shows that the crumb rubber has a rough surface and a large specific surface area, which increases the contact between the crumb rubber and the base asphalt, whereas the plasticized crumb rubber has a smoother surface. The plasticized crumb rubber also has a relatively loose flocculent structure with a large number of closely spaced surface voids.

\subsubsection{Additive}

The additive used in this study was Vestenamer ${ }^{\circledR}$ 8012, which was supplied by Evonik Corporation USA (Parsippany, NJ, USA) Vestenamer ${ }^{\circledR} 8012$, is a trans-polyoctenamer rubber used to improve the chemical bond between the crumb rubber and the base asphalt, and the properties of this additive are listed in Table 3.

Table 3. Basic properties of Vestenamer ${ }^{\circledR} 8012$.

\begin{tabular}{cc}
\hline Items & Tested Results \\
\hline Physical state & solid \\
Color & white \\
Form & granular \\
Glass transition temperature $\left({ }^{\circ} \mathrm{C}\right)$ & -65 \\
Melting point $\left({ }^{\circ} \mathrm{C}\right)$ & 54 \\
Density $\left(\mathrm{g} / \mathrm{cm}^{3}\right)$ & 0.91 \\
\hline
\end{tabular}

\subsection{Preparation and Aging of Asphalt Rubbers}

\subsubsection{Preparation of Asphalt Rubbers}

The total crumb rubber content was $20 \%$ by weight of the base asphalt; different asphalt rubbers were prepared containing untreated crumb rubber contents of $20 \%, 10 \%$ and $0 \%$ (corresponding to $0 \%, 10 \%$ and $20 \%$ plasticized crumb rubber). The blended additive was $5 \%$ of the total mass of the crumb rubber. Three asphalt rubber samples were labeled as follows: 1\# contained 20\% untreated crumb rubber; $2 \#$ contained $10 \%$ untreated crumb rubber and $10 \%$ plasticized crumb rubber; and $3 \#$ contained $20 \%$ of plasticized crumb rubber. The following preparation process was used: First, $400 \mathrm{~g}$ of the base asphalt were weighed, placed in a cylindrical stainless steel container and heated at $180{ }^{\circ} \mathrm{C}$. The two 60-mesh crumb rubbers and the additive were added to the SK 90\# base asphalt and mixed at $180{ }^{\circ} \mathrm{C}$ at a stirring rate of $500 \mathrm{rpm}$. Then, the asphalt rubbers were stirred at $5000 \mathrm{rpm}$ for $45 \mathrm{~min}$ at $180^{\circ} \mathrm{C}$ by a high-speed shear dispersion emulsifying machine. Finally, the three asphalt rubbers were developed at $180^{\circ} \mathrm{C}$ for $45 \mathrm{~min}$ and further tested.

\subsubsection{Aging of Asphalt Rubbers}

The standard rolling thin film oven test (RTFOT) was implemented following ASTM D2872 [29] to simulate short-term aging of the asphalt rubbers. Then, the RTFOT residues of the asphalt rubbers were subjected to long-term aging following the standard pressurized aging vessel (PAV) method (ASTM D6521) [30] at $100{ }^{\circ} \mathrm{C}$ under an air pressure of $2.10 \mathrm{MPa}$ for $20 \mathrm{~h}$ (1PAV) and $40 \mathrm{~h}$ (2PAV).

\subsection{Rheological Test of Asphalt Rubbers}

A dynamic shear rheometer (DSR) was used to conduct frequency sweep (FS) tests to evaluate the asphalt rubber crack resistance at low temperatures. The frequency range was $0.1-100 \mathrm{rad} / \mathrm{s}$, and the strain was $0.1 \%$ at temperatures of $\mathrm{PG}+10^{\circ} \mathrm{C}$ and $\mathrm{PG}+20^{\circ} \mathrm{C}$ (PG: performance grade). The diameter of the DSR rotor was $4 \mathrm{~mm}$, and the thickness of the samples was $2 \mathrm{~mm}$. 


\subsection{Microscopic Test Techniques}

\subsubsection{Fourier Transform Infrared Spectroscopy (FTIR)}

The Fourier transform infrared spectra of the three asphalt rubbers were obtained by using attenuated total reflection. The depth of the resulting infrared spectrogram is generally a few microns, such that this surface analysis technology can be used to perform rapid, non-destructive and in situ detection. The detection wavenumber range ranged from $4000 \mathrm{~cm}^{-1}$ to $400 \mathrm{~cm}^{-1}$, and the peaks of functional groups in the spectra were subsequently analyzed.

\subsubsection{Scanning Electron Microscope (SEM)}

A scanning electron microscope was used to observe the morphology of fractured cross-sections of the asphalt rubbers. The asphalt rubbers samples were coated with a gold thin film for the SEM tests.

\subsection{Interconversion between Linear Viscoelastic Material Functions}

In the developed DSR test specification, the reference temperature of the relaxation modulus master curve is increased from the low-temperature PG (performance grade) temperature by $10^{\circ} \mathrm{C}$ to be consistent with the BBR test temperature, such that the viscoelastic mechanical response obtained in the frequency domain can be mapped to the viscoelastic properties obtained in the time domain. The evaluation indexes of the relaxation modulus $G(60 \mathrm{~s})$ and the relaxation rate $m_{r}(60 \mathrm{~s})$ exhibited a good linear correlation with the creep stiffness modulus $S(60 \mathrm{~s})$ and the creep rate $m(60 \mathrm{~s})[31,32]$. The interconversion between the linear viscoelastic material functions developed by Christensen (given in Equation (1) below [33]) was used to convert the modulus from the frequency domain to the time domain:

$$
\left.G(t) \approx G^{\prime}(\omega)\right|_{\omega=2 / \pi t}
$$

where $G(t)$ is the relaxation modulus, $\mathrm{MPa}, G^{\prime}(\omega)$ is the storage modulus, $\mathrm{MPa}, \omega$ is the angular frequency, $\mathrm{rad} / \mathrm{s}$, and $t$ is the loading time, s.

\section{Results and Discussion}

\subsection{Master Curves of Storage Modulus for Different Aging Levels}

As the PG temperatures of the three asphalt rubbers were $-28{ }^{\circ} \mathrm{C}$, the frequency sweep test temperatures were $-18{ }^{\circ} \mathrm{C}$ and $-8{ }^{\circ} \mathrm{C}$ and the reference temperature was $-18{ }^{\circ} \mathrm{C}$. The master curves of the storage modulus for different aging levels were plotted using the time-temperature equivalence principle. Figure 5 shows the master curves of the storage modulus that were converted into the relaxation modulus.

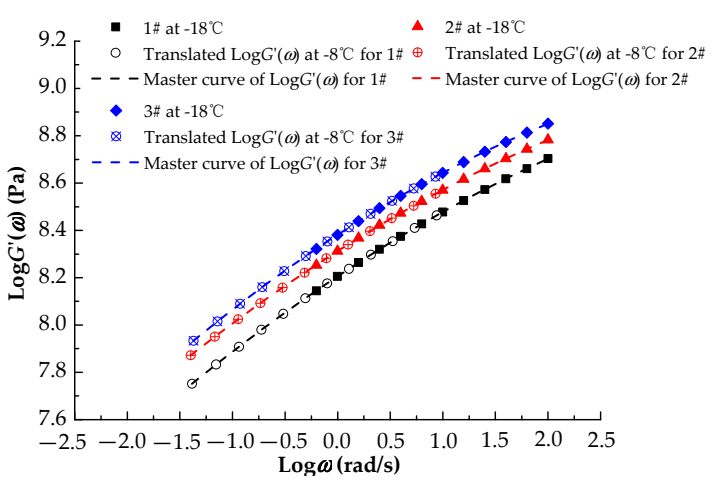

(a)

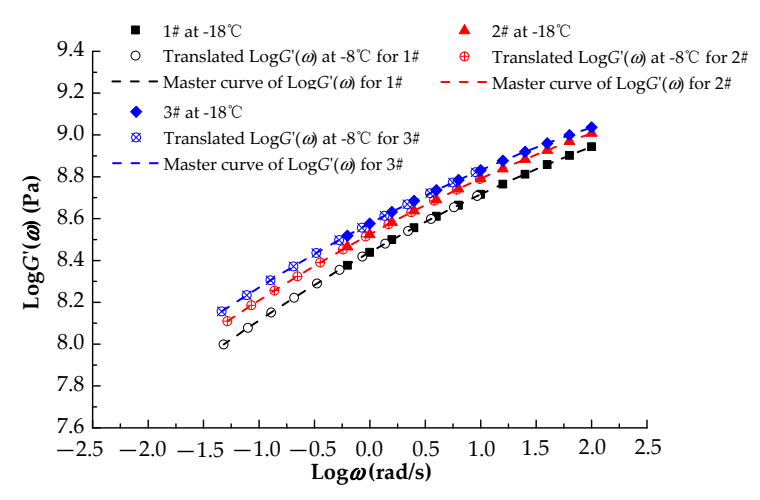

(b)

Figure 5. Cont. 


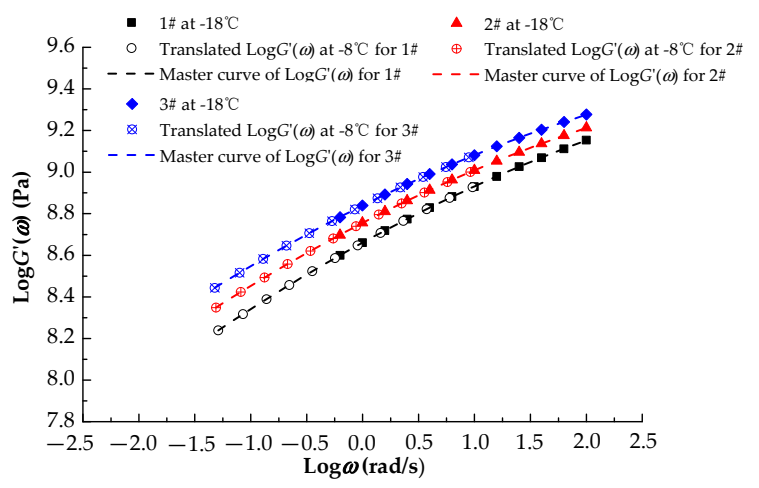

(c)

Figure 5. Master curves of storage modulus $G^{\prime}(\omega)$ for different aging levels. (a) RTFOT; (b) 1 pressurized aging vessel (PAV); (c) 2PAV.

In Figure 5, similar change trends are observed for the storage moduli, that is, the storage modulus increases with the plasticized crumb rubber content. This result is obtained because the cross-links in the plasticized crumb rubbers are cleaved by atmospheric pressure plasticization-the molecular chains are shortened, and the number of active groups at the end of the molecular chains increases, thereby strengthening the bond between the crumb rubber and the polar groups in the base asphalt. Compared with the storage moduli of $1 \#$, the storage moduli of $2 \#$ increase by at least $1.33 \%$ at $0.1 \mathrm{rad} / \mathrm{s}$ and $0.65 \%$ at $100 \mathrm{rad} / \mathrm{s}$, whereas the storage moduli of $3 \#$ increase by at least $1.98 \%$ at $0.1 \mathrm{rad} / \mathrm{s}$ and $1.04 \%$ at $100 \mathrm{rad} / \mathrm{s}$ for the three aging levels. The storage modulus increases with the aging level, which promotes deformation recovery. Table 4 shows the fitting functions of the storage modulus, for which the coefficients of determination are all greater than 0.99 .

Table 4. Fitting parameters of master curves of storage modulus for the three aging levels.

\begin{tabular}{|c|c|c|c|c|}
\hline \multirow{2}{*}{\multicolumn{2}{|c|}{ Aging Levels }} & \multicolumn{3}{|c|}{ Fitting Functions of Storage Modulus $y=a x^{2}+b x+c$} \\
\hline & & $\mathbf{a}$ & b & c \\
\hline \multirow{4}{*}{ RTFOT } & $1 \#$ & -0.02361 & 0.29532 & 8.20603 \\
\hline & 2\# & -0.02361 & 0.2822 & 8.31233 \\
\hline & $3 \#$ & -0.0276 & 0.2894 & 8.38175 \\
\hline & $1 \#$ & -0.02489 & 0.30172 & 8.43949 \\
\hline \multirow[t]{2}{*}{$1 \mathrm{PAV}$} & $2 \#$ & -0.02497 & 0.29138 & 8.52523 \\
\hline & $3 \#$ & -0.02553 & 0.2806 & 8.577 \\
\hline \multirow{3}{*}{ 2PAV } & $1 \#$ & -0.02459 & 0.29507 & 8.66109 \\
\hline & $2 \#$ & -0.02481 & 0.27793 & 8.75594 \\
\hline & $3 \#$ & -0.02443 & 0.26712 & 8.83934 \\
\hline
\end{tabular}

\subsection{Master Curves of Relaxation Modulus for Different Aging Levels}

Equation (1) was used to convert the storage moduli $G^{\prime}(\omega)$ in Figure 5 to the relaxation moduli for the three asphalt rubbers for the different aging levels; the master curves for the relaxation modulus are displayed in Figure 6.

Figure 6 shows that the relaxation modulus increases with the plasticized crumb content. Compared with the storage moduli of $1 \#$, the relaxation moduli of $2 \#$ increase by at least $1.05 \%$ at $0.1 \mathrm{rad} / \mathrm{s}$ and $0.82 \%$ at $100 \mathrm{rad} / \mathrm{s}$, whereas the relaxation moduli of $3 \#$ increase by at least $1.69 \%$ at $0.1 \mathrm{rad} / \mathrm{s}$ and $1.30 \%$ at $100 \mathrm{rad} / \mathrm{s}$ for the three aging levels. Aging causes a considerable increase in the relaxation modulus. There is a decrease in the relaxation modulus, going from the 2PAV result to the 1PAV result to the RTFOT result. Table 5 shows the fitting functions of the relaxation modulus, for which the coefficients of determination are all greater than 0.99 . 


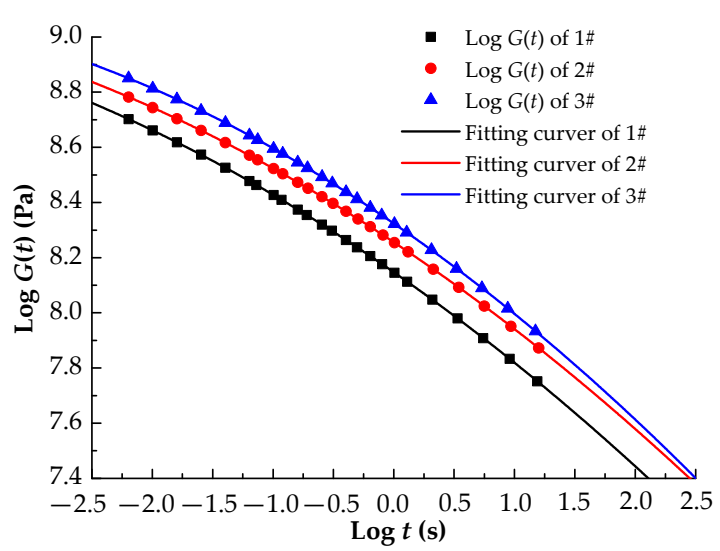

(a)

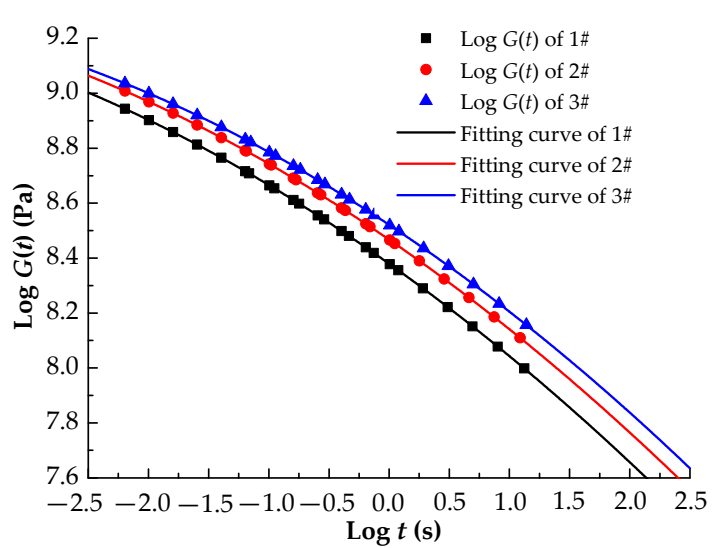

(b)

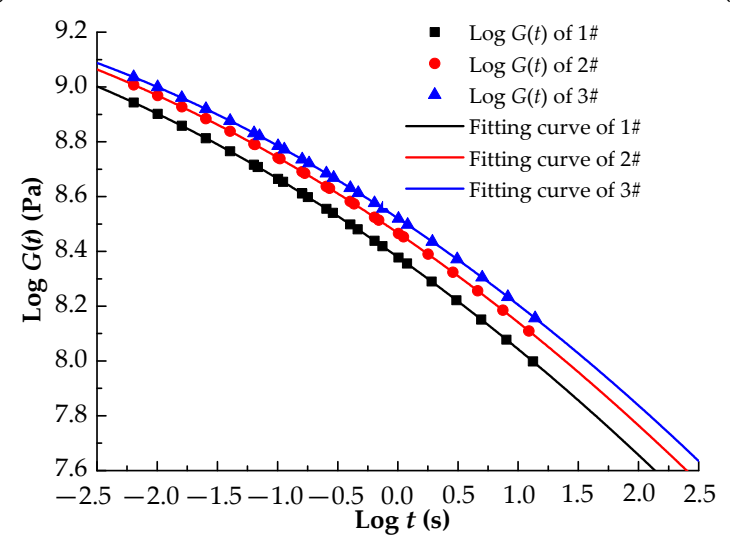

(c)

Figure 6. Master curves of relaxation modulus $G(t)$ for different aging levels. (a) RTFOT; (b) 1PAV; (c) 2PAV.

Table 5. Fitting parameters of master curves of relaxation modulus for the three aging levels.

\begin{tabular}{|c|c|c|c|c|}
\hline \multirow{2}{*}{\multicolumn{2}{|c|}{ Aging Levels }} & \multicolumn{3}{|c|}{ Fitting Functions of Relaxation Modulus $y=a x^{2}+b x+c$} \\
\hline & & $\mathbf{a}$ & b & c \\
\hline \multirow{4}{*}{ RTFOT } & $1 \#$ & -0.02361 & -0.30458 & 8.1472 \\
\hline & $2 \#$ & -0.0236 & -0.2914 & 8.25608 \\
\hline & $3 \#$ & -0.0276 & -0.30025 & 8.32392 \\
\hline & $1 \#$ & -0.02489 & -0.31148 & 8.37936 \\
\hline \multirow[t]{2}{*}{ 1PAV } & 2\# & -0.02497 & -0.30117 & 8.46712 \\
\hline & $3 \#$ & -0.02553 & -0.29061 & 8.52099 \\
\hline \multirow{3}{*}{ 2PAV } & $1 \#$ & -0.02459 & -0.30472 & 8.60228 \\
\hline & 2\# & -0.02481 & -0.28766 & 8.70448 \\
\hline & $3 \#$ & -0.02443 & -0.2767 & 8.78601 \\
\hline
\end{tabular}

\subsection{Converted Evaluation Index of Low-Temperature Rheological Properties}

Two criteria must be satisfied for the BBR test at $60 \mathrm{~s}$ of loading time. The creep stiffness modulus should be smaller than $300 \mathrm{MPa}$, and the m-value should be larger than 0.300 . The smaller the creep stiffness or the larger the m-value, the higher the low-temperature performance. Figures 7 and 8 show the relaxation modulus $G(60 \mathrm{~s})$ and the relaxation rate $m_{r}(60 \mathrm{~s})$ as converted evaluation indexes of the low-temperature rheological properties.

Although aging significantly increases the relaxation modulus $G(60 \mathrm{~s})$, the relaxation modulus $G(60 \mathrm{~s})$ is less than $300 \mathrm{MPa}$, and the relaxation rate $m_{r}(60 \mathrm{~s})$ is greater than 0.300 in Figures 7 and 8 . Aging has little effect on the relaxation rate $m_{r}(60 \mathrm{~s})$ of $1 \#$ and $2 \#$, and the relaxation rate $m_{r}(60 \mathrm{~s})$ of 
3\# decreases as the aging level increases, which shows that aging decreases the low-temperature relaxation ability of asphalt rubber. The plasticized crumb rubber content significantly affects the relaxation modulus $G(60$ s). The largest relaxation moduli are observed for $3 \#$ (which contains $20 \%$ plasticized crumb rubber) for the three aging levels, whereas the plasticized crumb rubber content has no clear effect on the relaxation rate $m_{r}(60 \mathrm{~s})$. The maximum differences in the relaxation rates of $1 \#$, 2\# and 3\# are $6.13 \%, 4.89 \%$ and $7.86 \%$, respectively. Additionally, an analysis of variance was employed to evaluate the influence of crumb rubber contents and aging on the low-temperature performance of asphalt rubber statistically. The standard deviations of relaxation moduli are $31.466 \mathrm{MPa}, 42.453 \mathrm{MPa}$ and 58.674 MPa for 1\#, 2\# and 3\#, respectively. Accordingly, the standard deviations of relaxation rates are $0.006,0.008$ and 0.017 for $1 \#, 2 \#$ and $3 \#$, respectively. The above statistical analysis indicates that the differences in low-temperature performance of asphalt rubbers caused by different aging levels become more significant with the increase in plasticized crumb rubber content.

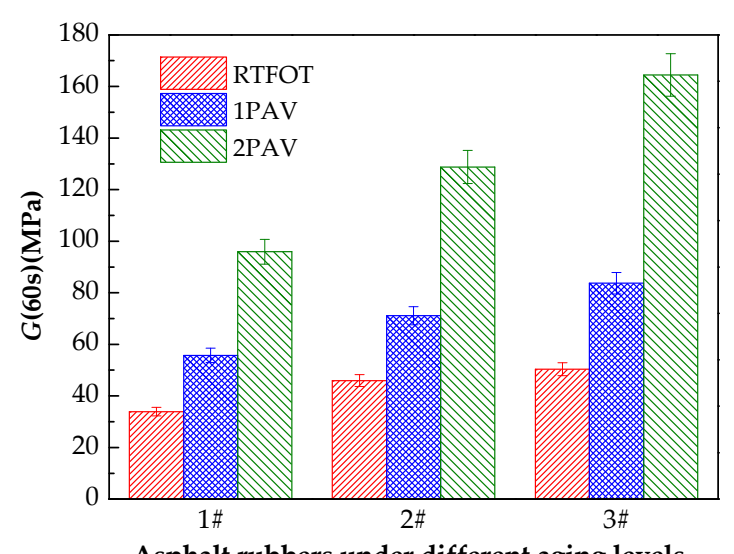

Asphalt rubbers under different aging levels

Figure 7. G(60s) for different aging levels.

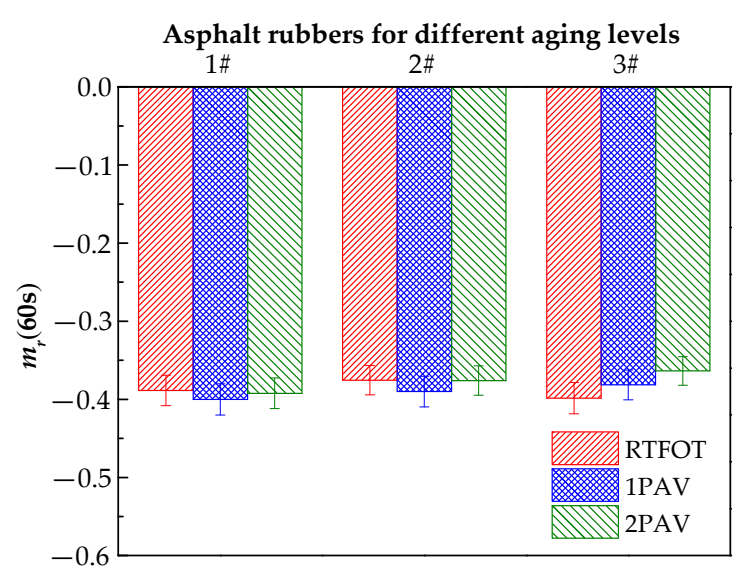

Figure 8. $m_{r}(60 \mathrm{~s})$ for different aging levels.

\subsection{FTIR}

Table 6 lists the main functional groups used to identify the changes in the molecular structure of the asphalt rubbers with different crumb rubber and plasticized crumb rubber contents for the three aging levels [34-37], and the intensities of the absorption peaks at $1696 \mathrm{~cm}^{-1}, 1596 \mathrm{~cm}^{-1}$ and $1030 \mathrm{~cm}^{-1}$ are listed in Table 7. Figure 9 shows the infrared spectra of three asphalt rubbers. 
Table 6. Functional groups in asphalt rubbers [34-37].

\begin{tabular}{cc}
\hline Wavenumber $\left(\mathbf{c m}^{-\mathbf{1}}\right)$ & Functional Groups \\
\hline 2918 & asymmetric stretching vibrations of $-\mathrm{CH}_{2}-$ \\
2849 & symmetric stretching vibrations of $-\mathrm{CH}_{2}-$ \\
1696 & stretching of $\mathrm{C}=\mathrm{O}$ \\
1596 & stretching of $\mathrm{C}=\mathrm{C}$ \\
1456 & scissor vibration of $-\mathrm{CH}_{2}-$ \\
1375 & deformation vibration of $-\mathrm{CH}_{3}$ \\
1105 & stretching vibration of $\mathrm{C}-\mathrm{O}$ \\
1030 & stretching vibration of $\mathrm{S}=\mathrm{O}$ \\
$650-1000$ & substitution region of benzene ring \\
\hline
\end{tabular}

Table 7. Intensities of three absorption peaks.

\begin{tabular}{ccccc}
\hline \multirow{2}{*}{ Wavenumber $\left(\mathbf{c m}^{-\mathbf{1}}\right)$} & \multirow{2}{*}{ Aging Levels } & \multicolumn{3}{c}{ Intensities } \\
\cline { 2 - 5 } & & $\mathbf{1 \#}$ & $\mathbf{2 \#}$ & 3\# \\
\hline \multirow{3}{*}{1696} & RTFOT & 0.00818 & 0.00583 & 0.0083 \\
\cline { 2 - 5 } & 1PAV & 0.01476 & 0.01117 & 0.01387 \\
\cline { 2 - 5 } & 2PAV & 0.01435 & 0.0175 & 0.01995 \\
\hline \multirow{2}{*}{1596} & RTFOT & 0.02042 & 0.01959 & 0.02305 \\
\cline { 2 - 5 } & 1PAV & 0.02443 & 0.01982 & 0.02546 \\
\hline \multirow{2}{*}{1030} & 2PAV & 0.02087 & 0.02419 & 0.02724 \\
\cline { 2 - 5 } & RTFOT & 0.02962 & 0.02972 & 0.03184 \\
\cline { 2 - 5 } & 1PAV & 0.03514 & 0.02714 & 0.04585 \\
\hline & 2PAV & 0.03604 & 0.04153 & 0.04475 \\
\hline
\end{tabular}

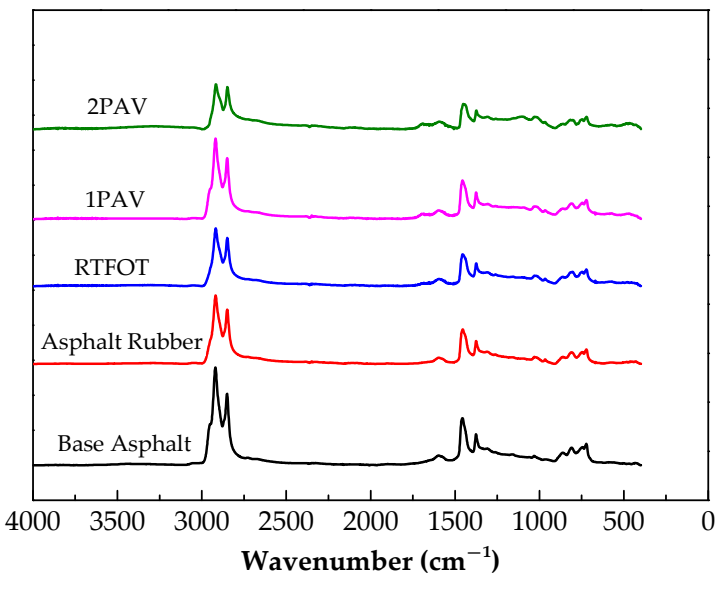

(a)

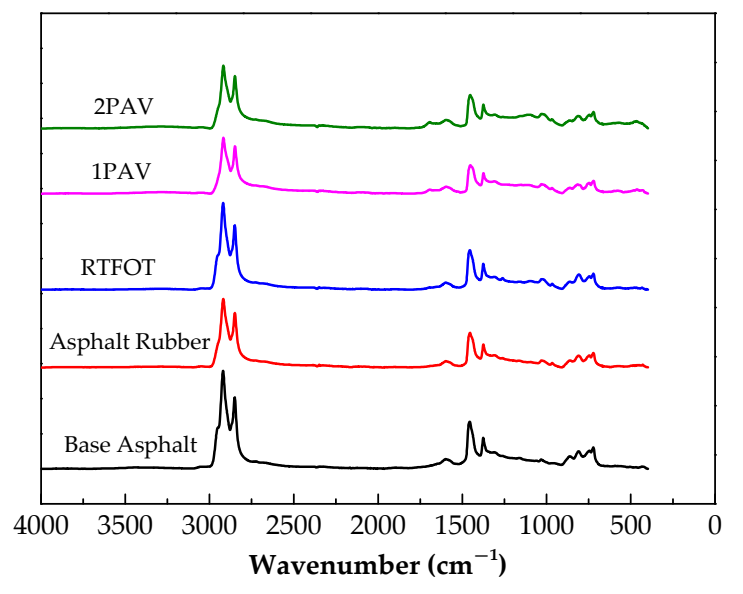

(b)

Figure 9. Cont. 


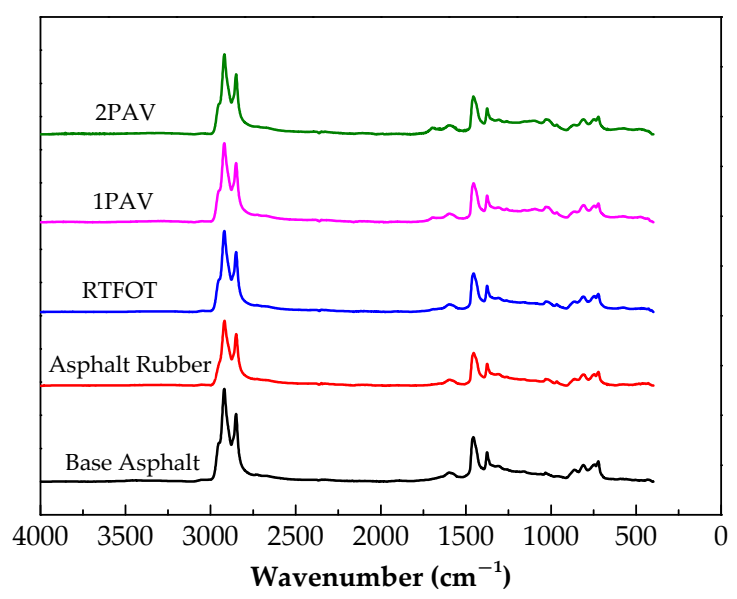

(c)

Figure 9. FTIR spectra of asphalt rubbers for different aging levels. (a) 1\#; (b) 2\#; (c) 3\#.

There is no clear difference between the FTIR spectra of the asphalt rubber and the base asphalt in Figure 9, showing that the ordinary and plasticized crumb rubbers are physically blended with the base asphalt, and the absorption of the lighter components by the crumb rubber particles produces a swelling reaction. The four strong absorption peaks at $2918 \mathrm{~cm}^{-1}, 2849 \mathrm{~cm}^{-1}, 1456 \mathrm{~cm}^{-1}$ and $1375 \mathrm{~cm}^{-1}$ for $1 \#, 2 \#$ and $3 \#$ correspond to the asymmetric stretching, symmetric stretching and scissor vibrations of $-\mathrm{CH}_{2}-$ and the deformation vibration of $-\mathrm{CH}_{3}$, respectively. These vibrations are unchanged by adding crumb rubber to the base asphalt. The absorption peaks between $1000 \mathrm{~cm}^{-1}$ and $650 \mathrm{~cm}^{-1}$ that represent the $\mathrm{C}-\mathrm{C}$ skeleton vibration and out-of-plane bending of $\mathrm{C}-\mathrm{H}$ remain fairly consistent with the values given in Table 7 .

However, there are significant differences among the three samples in the intensities of the absorption peaks at $1696 \mathrm{~cm}^{-1}, 1596 \mathrm{~cm}^{-1}$ and $1030 \mathrm{~cm}^{-1}$ that correspond to $\mathrm{C}=\mathrm{O}$ stretching, $\mathrm{C}=\mathrm{C}$ stretching and the $\mathrm{S}=\mathrm{O}$ stretching vibration, respectively. The strongest peaks are, in general, under 2PAV for 1\#, 2\# and 3\#, and the peak intensities under 1PAV are greater than those of under RTFOT, which is attributed to 2PAV with longer aging oxidation time. The peak intensities for $3 \#$ under 2PAV and $1 \mathrm{PAV}$ are approximately equal and higher than under RTFOT. The highest peak intensities of all the samples are obtained for 3\# under 2PAV, followed by sample 2\#. Considering that 2\# and 3\# contain plasticized crumb rubber, parts of the molecular chains, such as $\mathrm{C}-\mathrm{S}$ and S-S, are oxidized and broken during plasticization, which is easier to combine with oxygen after aging. Consequently, strong absorption peaks of $\mathrm{C}=\mathrm{O}$ at $1696 \mathrm{~cm}^{-1}$ and $\mathrm{S}=\mathrm{O}$ at $1030 \mathrm{~cm}^{-1}$ appear, especially for $\mathrm{S}=\mathrm{O}$ of $3 \#$ at $1030 \mathrm{~cm}^{-1}$.

\subsection{SEM}

Scanning electron microscopy (SEM) was used to observe and analyze the microscopic morphology of the asphalt rubbers containing heterogeneous crumb rubber and the bonding between the crumb rubber and the base asphalt for the three aging levels. The micrographs are presented in Figure 10.

Figure 10 shows that the bonds between the crumb rubber and the base asphalt deteriorate as the aging level increases. The asphalt coating of the crumb rubbers deteriorates, the crumb rubber gradually separates from the base asphalt, and the interface between the base asphalt and crumb rubber becomes more distinct, showing that aging reduces the efficacy of the blending between the crumb rubber and the base asphalt and the performance of the asphalt rubber. This result is obtained because aging converts the light components in the base asphalt into macromolecular resins and asphaltenes that are weakly compatible with crumb rubbers, thereby weakening the interfacial interaction between the crumb rubber and the base asphalt. 


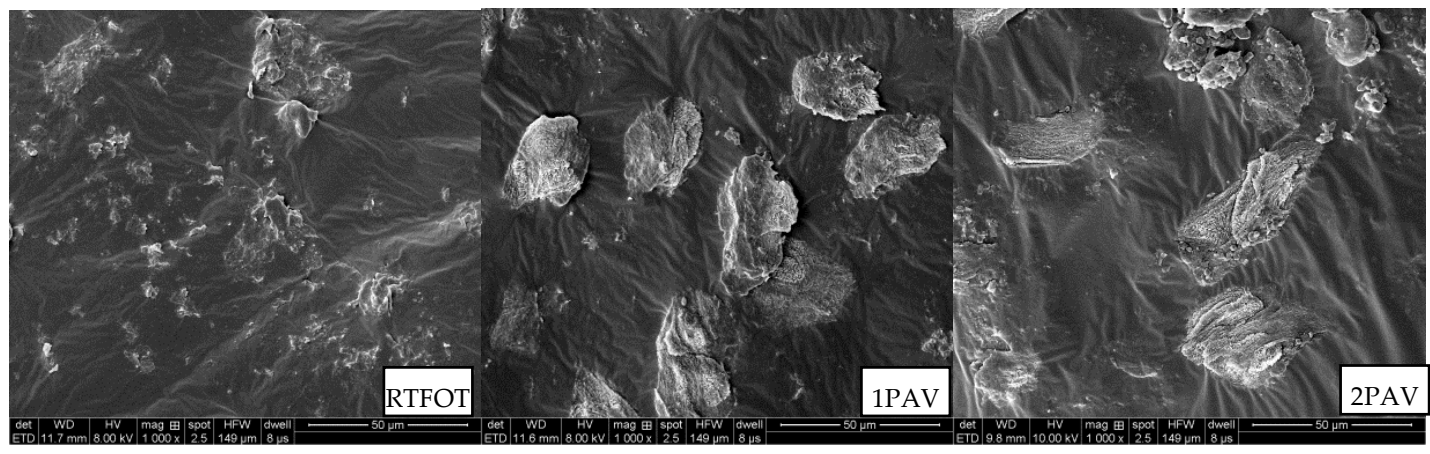

(a)

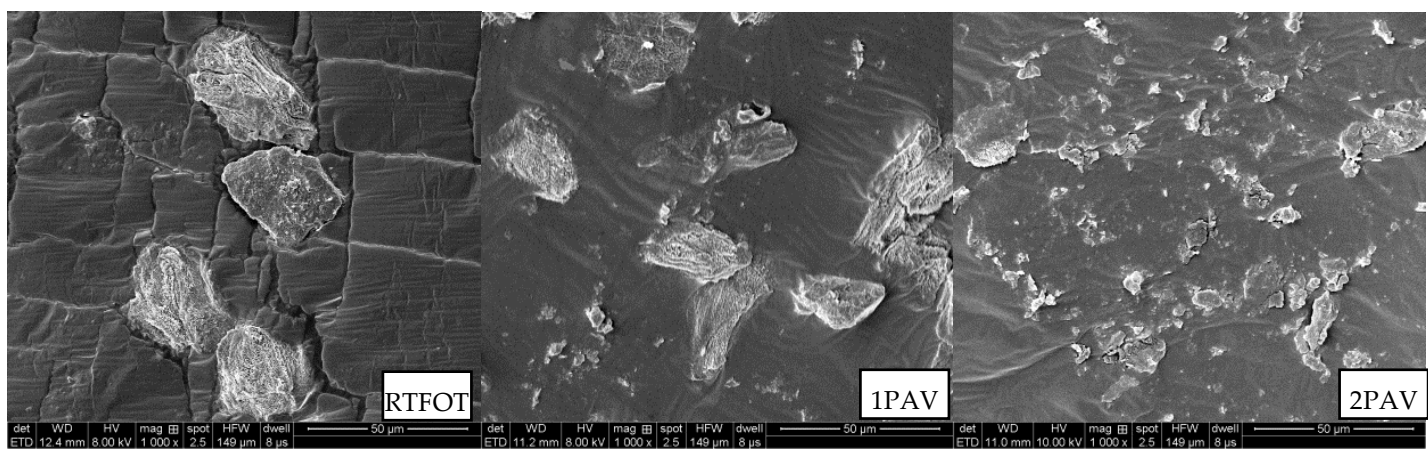

(b)

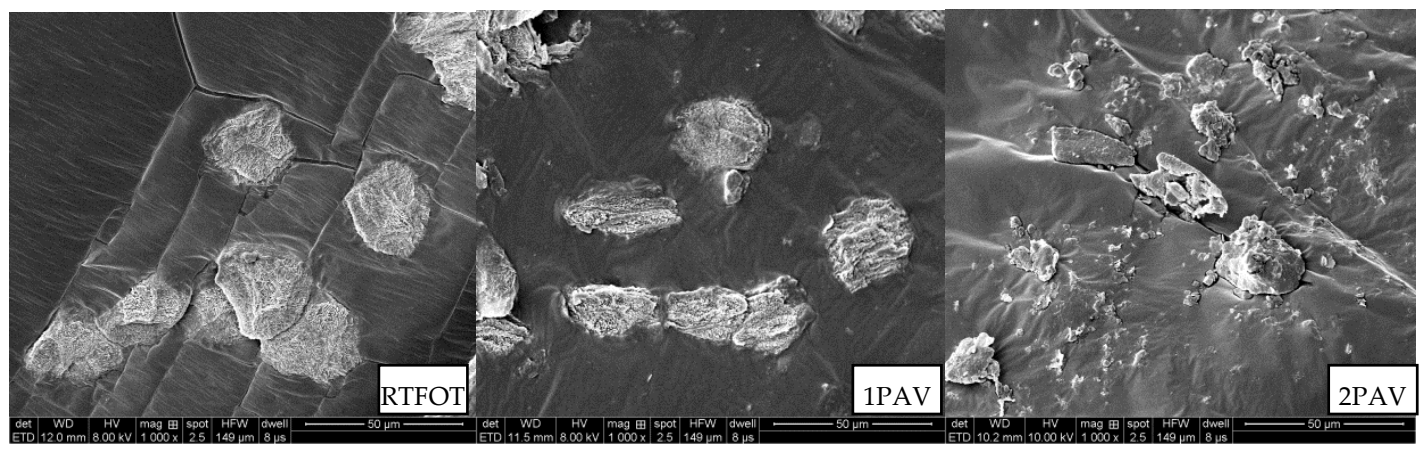

(c)

Figure 10. SEM images of asphalt rubbers for different aging levels. (a) 1\#; (b) 2\#; (c) 3\#.

The interface stripping degree of $1 \#$ is less than those of $2 \#$ and $3 \#$, that is, the particle core of $1 \#$ remains more intact than for the other two samples. Aging gradually strips fine particles off the crumb rubber particles in 2\# and 3\#, especially for 3\# under 2PAV. These stripped fine crumb rubber particles destroy the cross-linked network formed by the crumb rubber and the base asphalt. This result is obtained because molecular chains are broken in the plasticized crumb rubber in $2 \#$ and 3\#. Aging destroys the interaction between the plasticized crumb rubber and the base asphalt, making it difficult for the plasticized crumb rubber to form particle cores. However, the crumb rubber in $1 \#$ is untreated and therefore sustains less damage under aging than the plasticized crumb rubber, such that the interfacial bonding between the untreated crumb rubber and the base asphalt remains relatively intact.

\section{Conclusions}

The impact of different aging levels on the low-temperature rheological properties of asphalt rubber prepared using untreated and plasticized crumb rubbers was investigated in this study. The evolution of the chemical groups and interfacial fusion between the base asphalt and the crumb 
rubbers were analyzed for asphalt rubbers containing heterogeneous crumb rubbers for different aging levels. The following conclusions were drawn from the rheological properties and microscopic characterization of the samples used in the study:

(1) The storage moduli of asphalt rubbers containing heterogeneous crumb rubbers increased with the plasticized rubber content and the aging level. An internal conversion relationship between the linear viscoelastic functions was used to obtain a changing trend for the converted relaxation modulus that was consistent with that of the storage modulus. Increasing the plasticized crumb rubber content and the aging level decreased the relaxation rate and the low-temperature performance of the asphalt rubber.

(2) No new absorption peaks appeared after adding the untreated and plasticized crumb rubbers to the base asphalt, showing that the crumb rubber was physically blended with the asphalt. Aging significantly affected the $\mathrm{C}=\mathrm{O}, \mathrm{C}=\mathrm{C}$ and $\mathrm{S}=\mathrm{O}$ absorption peaks, where the highest peak intensities were obtained for the sample containing only untreated crumb rubber. Low peak intensities were observed for the samples containing plasticized crumb rubber because plasticization produced broken molecular chains.

(3) The bonding between the crumb rubber and the base asphalt deteriorated as the aging level increased: the crumb rubbers gradually separated from the base asphalt, and the interface between the crumb rubber and the base asphalt gradually became distinct. Fine particles were stripped off the plasticized crumb rubbers, making particle core formation difficult, whereas the particle cores of the asphalt rubbers containing untreated crumb rubbers remained relatively intact.

Previous studies have shown that Vestanamer can improve the compatibility of crumb rubber and asphalt, and improve the storage stability of asphalt rubber. This paper investigated the low-temperature performance of asphalt rubber prepared by adding Vestanamer, and the low-temperature performance indexes met the specification requirements. The further research could consider adding a comparison group of asphalt rubber prepared without Vestanamer to compare and analyze the effect of Vestanamer on the low-temperature performance of asphalt rubber.

Author Contributions: M.C. conceived and designed the experiments; M.W. and F.H. performed the experiments; Y.Z. analyzed the data; M.C. wrote the paper; J.P. and J.Z. provided the methodology and project administration. All authors have read and agreed to the published version of the manuscript.

Funding: This work was supported by the National Natural Science Foundation of China (No. 51408047), the Special Fund for Basic Scientific Research of Central College of Chang'an University (No. 300102319205), and the Student's Platform for Innovation and Entrepreneurship Training Program (Nos. 201910710154, 201910710585 and S202010710220).

Acknowledgments: The untreated and plasticized crumb rubbers were provided by China Rubber Resource Regeneration (Qingdao) Co. Ltd.

Conflicts of Interest: The authors declare no conflict of interest.

\section{References}

1. Xiao, F.P.; Amirkhanian, S.N.; Shen, J.N.; Putmana, B. Influences of Crumb Rubber Size and Type on Reclaimed Asphalt Pavement (RAP) Mixtures. Constr. Build. Mater. 2009, 23, 1028-1034. [CrossRef]

2. Chen, H. Study on the Influence of Crumb Rubber Recycled from Waste Tires with Different Compositions on Asphalt Performance; Wuhan University of Technology: Wuhan, China, 2018. (In Chinese)

3. Rahman, M.T.; Mohajerani, A.; Giustozzi, F. Recycling of Waste Materials for Asphalt Concrete and Bitumen: A Review. Materials 2020, 13, 1495. [CrossRef]

4. Li, B.; Zhou, J.N.; Zhang, Z.H.; Yang, X.L.; Wu, Y. Effect of Short-Term Aging on Asphalt Modified Using Microwave Activation Crumb Rubber. Materials 2019, 12, 1039. [CrossRef]

5. Yu, J.M.; Ren, Z.B.; Yu, H.Y.; Wang, D.Y.; Svetlana, S.; Korolev, E.; Gao, Z.M.; Guo, F. Modification of Asphalt Rubber with Nanoclay towards Enhanced Storage Stability. Materials 2018, 11, 2093. [CrossRef]

6. Wang, D.Y.; Li, D.N.; Yan, J.H.; Leng, Z.; Wu, Y.M.; Yu, J.M.; Yu, H.Y. Rheological and Chemical Characteristic of Warm Asphalt Rubber Binders and Their Liquid Phases. Constr. Build. Mater. 2018, 193, 547-556. [CrossRef] 
7. Tang, J.C.; Zhu, C.Z.; Zhang, H.L.; Xu, G.Q.; Xiao, F.P.; Amirkhanian, S. Effect of Liquid ASAs on the Rheological Properties of Crumb Rubber Modified Asphalt. Constr. Build. Mater. 2019, 194, 238-246. [CrossRef]

8. Dong, Z.J.; Zhou, T.; Luan, H.; Williams, R.C.; Wang, P.; Leng, Z. Composite Modification Mechanism of Blended Bio-Asphalt Combining Styrene-Butadiene-Styrene with Crumb Rubber: A Sustainable and Environmental-Friendly Solution for Wastes. J. Clean. Prod. 2019, 214, 593-605. [CrossRef]

9. Zhang, L.; Xing, C.; Gao, F.; Li, T.S.; Tan, Y.Q. Using DSR and MSCR Tests to Characterize High Temperature Performance of Different Rubber Modified Asphalt. Constr. Build. Mater. 2016, 127, 466-474. [CrossRef]

10. Lei, Y.; Wang, H.N.; Fini, H.E.; You, Z.P.; Yang, X.; Gao, J.F.; Dong, S.; Jiang, G. Evaluation of the Effect of Bio-Oil on the High-Temperature Performance of Rubber Modified Asphalt. Constr. Build. Mater. 2018, 191, 692-701. [CrossRef]

11. Chen, Z.X.; Pei, J.Z.; Wang, T.; Amirkhanian, S. High Temperature Rheological Characteristics of Activated Crumb Rubber Modified Asphalts. Constr. Build. Mater. 2018, 194, 122-131. [CrossRef]

12. Xu, J.; Li, R.; Liu, T.; Pei, J.Z.; Li, Y.K.; Luo, Q.H. Study on the Effect of Microwave Processing on Asphalt-Rubber. Materials 2020, 13, 411. [CrossRef] [PubMed]

13. Singh, D.; Sawant, D.; Xiao, F.P. High and Intermediate Temperature Performance Evaluation of Crumb Rubber Modified Binders with RAP. Transp. Geotech. 2017, 10, 13-21. [CrossRef]

14. Singh, D.; Ashish, P.K.; Ajayshankar, J. Influence of Particle and Interaction Effects of Different Sizes of Crumb Rubber on Rheological Performance Parameters of Binders. J. Mater. Civ. Eng. 2018, 30, 04018066. [CrossRef]

15. Li, J.; Xiao, F.P.; Amirkhanian, S.N. High Temperature Rheological Characteristics of Plasma-Treated Crumb Rubber Modified Binders. Constr. Build. Mater. 2020, 236, 1-14. [CrossRef]

16. Ameri, M.; Seif, M.R.; Abbasi, M.; Khiavi, A.K. Viscoelastic Fatigue Resistance of Asphalt Binders Modified with Crumb Rubber and Styrene Butadiene Polymer. Petrol. Sci. Technol. 2017, 35, 30-36. [CrossRef]

17. Yu, J.M.; Yu, X.S.; Gao, Z.M.; Guo, F.; Wang, D.Y.; Yu, H.Y. Fatigue Resistance Characterization of Warm Asphalt Rubber by Multiple Approaches. Appl. Sci. 2018, 8, 1495. [CrossRef]

18. Tan, Y.Q.; Fu, Y.K.; Ji, L.; Zhang, L. Low-Temperature Evaluation Index of Rubber Asphalt. J. Harbin Inst. Technol. 2016, 48, 66-70. (In Chinese) [CrossRef]

19. Li, B.; Wang, J.; Cao, G.; Wang, C.H.; Yang, X.L. Influence Mechanism of Crumb Rubber Characteristics on High-Temperature Performance for Rubber Modified Asphalt Binder. J. Basic Sci. Eng. 2017, 25, 347-355. (In Chinese) [CrossRef]

20. He, L.; Ling, T.Q.; Ma, Y.; Ma, T.; Huang, X.M. Rheological Properties of Warm Mix Asphalt Rubber in Wide Range of Pavement Temperature. J. Traffic Transp. Eng. 2015, 15, 1-9. (In Chinese)

21. He, L.; Ma, Y.; Ling, T.Q.; Ma, T.; Huang, X.M. Analysis on Crumb Rubber Modified Asphalt and Its Aging Characteristics on Microscale. J. Funct. Mater. 2015, 46, 21093-21098. (In Chinese)

22. Ziari, H.; Goli, A.; Amini, A. Effect of Crumb Rubber Modifier on the Performance Properties of Rubberized Binders. J. Mater. Civ. Eng. 2016, 28, 04016156. [CrossRef]

23. Puga, K.L.N.N.; Williams, R.C. Low Temperature Performance of Laboratory Produced Asphalt Rubber (AR) Mixes Containing Polyoctenamer. Constr. Build. Mater. 2016, 112, 1046-1053. [CrossRef]

24. Li, B.L.; Huang, W.D.; Tang, N.P.; Hu, J.Y.; Peng, L.; Guan, W.Y.; Xiao, F.P.; Shan, Z.P. Evolution of Components Distribution and Its Effect on Low Temperature Properties of Terminal Blend Rubberized Asphalt Binder. Constr. Build. Mater. 2017, 136, 598-608. [CrossRef]

25. Yadollahi, G.; Mollahosseini, H.S. Improving the performance of Crumb Rubber bitumen by means of Poly Phosphoric Acid (PPA) and Vestenamer additives. Constr. Build. Mater. 2011, 25, 3108-3116. [CrossRef]

26. Wang, Y.H.; Chen, Y.K.; Rodrigue, D. Production of Thermoplastic Elastomers Based on Recycled PE and Ground Tire Rubber: Morphology, Mechanical Properties and Effect of Compatibilizer Addition. Int. Polym. Proc. 2018, 33, 525-534. [CrossRef]

27. Xiao, P.; Jiang, D.A.; Wu, M.P. Grey Relational Analysis of Thermal Oxidative Water Aging Performances of TOR Rubber Asphalts. J. Nanjing Univ. Sci. Technol. 2012, 36, 1065-1069. (In Chinese)

28. Zhu, Y.F.; Jiang, P. Viscosity-Temperature Characteristics and Pavement Performance Rubber-modified Asphalt Added with Domestic TOR. Mater. Rev. 2016, 30, 134-139. (In Chinese) [CrossRef]

29. ASTM. Standard Test Method for Effect of Heat and Air on a Moving Film of Asphalt (Rolling Thin-Film Oven Test); ASTM International: West Conshohocken, PA, USA, 2004. 
30. ASTM. Standard Standard Practice for Accelerated Aging of Asphalt Binder Using a Pressurized Aging Vessel (PAV); ASTM International: West Conshohocken, PA, USA, 2013.

31. AASHTO XXX-12. Draft Standard Method of Test for Determining the Low Temperature Rheological Properties of Asphalt Binder Using A Dynamic Shear Rheometer (DSR); American Association of State Highway and Transportation Officials: Washington, DC, USA, 2012.

32. Farrar, M.; Sui, C.; Salmans, S.; Qin, Q. Determining the Low-Temperature Rheological Properties of Asphalt Binder Using a Dynamic Shear Rheometer (DSR); Report 4FP 08; Western Research Institute: Laramie, WY, USA, 2015.

33. Christensen, R.M. Theory of Viscoelasticity: An. Introduction; Academic Press: New York, NY, USA, 1982.

34. Hou, X.D.; Lv, S.T.; Chen, Z.; Xiao, F.P. Applications of Fourier Transform Infrared Spectroscopy Technologies on Asphalt Materials. Measurement 2018, 121, 304-316. [CrossRef]

35. Li, R.Y.; Xiao, F.P.; Amirkhanian, S.; You, Z.P.; Huang, J. Developments of Nano Materials and Technologies on Asphalt Materials-A Review. Constr. Build. Mater. 2017, 143, 633-648. [CrossRef]

36. Yao, H.; Dai, Q.L.; You, Z.P. Fourier Transform Infrared Spectroscopy Characterization of Aging-Related Properties of Original and Nano-Modified Asphalt Binders. Constr. Build. Mater. 2015, 101, 1078-1087. [CrossRef]

37. Chen, T.; Ma, T.; Huang, X.M.; Guan, Y.S.; Zhang, Z.X.; Tang, F.L. The Performance of Hot-Recycling Asphalt Binder Containing Crumb Rubber Modified Asphalt Based on Physiochemical and Rheological Measurements. Constr. Build. Mater. 2019, 226, 83-93. [CrossRef]

(C) 2020 by the authors. Licensee MDPI, Basel, Switzerland. This article is an open access article distributed under the terms and conditions of the Creative Commons Attribution (CC BY) license (http://creativecommons.org/licenses/by/4.0/). 